\title{
Para comprender Aparecida
}

\author{
Víctor Codina S.J, \\ Universidad Católica Boliviana, \\ Centro de Espiritualidad Ignaciana, \\ Cochabamba, Bolivia.
}

\section{Interrogantes y perplejidad ante Aparecida}

¿Cómo abordar el Documento de Aparecida? Esta es la primera pregunta que uno se hace ante el Documento conclusivo oficial de Aparecida 2007. No es fácil introducir a una lectura y comentario de un Documento de más de 200 páginas y 554 números. Habría que comenzar por situar este Documento en el caminar de la Iglesia de América Latina y del Caribe, un proceso que comenzó en Río de Janeiro (1955) y siguió en Medellín (1968), Puebla (1979) y Santo Domingo (1992), con diferentes aportes, pero en una continuidad de querer configurar una Iglesia cercana al pueblo, anunciadora del evangelio de Jesús, que sea realmente liberación de toda muerte, de toda injusticia, de toda pobreza ${ }^{1}$. Una vez establecida esta continuidad habría que preguntarse cuál es la novedad de Aparecida en este caminar. ¿Dice Aparecida algo realmente nuevo?

Antes de Aparecida habían surgido en la Iglesia de América Latina y del Caribe muchos temores. ¿Volvería realmente a haber una Conferencia de América Latina y del Caribe y no sólo un Sínodo sobre América Latina en Roma? ¿Se retomaría el método latinoamericano del ver, juzgar y actuar, que en Santo Domingo se había abandonado? ¿Se reafirmaría la opción por los pobres, por las

* Publicado también en la revista Cuarto Intermedio, Cochabamba, noviembre, 2007.

1. Para comprender el contexto histórico de Aparecida se puede consultar V. Codina, "Hacia la Conferencia de Aparecida 2007", en Cuarto intermedio 82 (febrero 2007) 3-18. 
comunidades de base, por las culturas, recordaría a los mártires, confirmaría el protagonismo de los laicos en la evangelización? ¿Defendería a las mujeres, la tierra y los derechos humanos?

Se puede decir que Aparecida ha disipado estos temores. Ha sido mejor de lo que se temía, mucho mejor que Santo Domingo. Se ha vuelto al método latinoamericano y se han asumido las opciones y orientaciones de las anteriores conferencias. No hay un retroceso, se ha recuperado lo mejor de la tradición eclesial de América latina y del Caribe.

También antes de Aparecida se expresaron muchos deseos de que la Iglesia afrontase los desafíos que habían surgido del nuevo contexto social, económico, político y eclesial, un replanteo, por ejemplo, de los ministerios, de la pastoral matrimonial y familiar, del diálogo intercultural... ¿Ha respondido Aparecida a estas expectativas? Según algunos, Aparecida ha sido, ciertamente, mejor de lo que se temía, pero peor de lo que esperaba y se soñaba.

Después de Aparecida van surgiendo comentarios de todo tipo. Para algunos, el Documento de Aparecida es lo mejor del magisterio latinoamericano, se ha cerrado definitivamente la cristiandad, nos ha dado una gran sorpresa. Otros son mucho más críticos, afirman que no hay nada nuevo, que es una ocasión perdida. La inmensa mayoría matiza más, habla de luces y sombras.

\section{Luces y sombras}

Entre las luces se destaca el haber retomado el método inductivo de Gaudium et Spes, el haber asumido el tema de la vida como eje central del Documento, el centrarse en la necesidad de ser discípulos y misioneros de Jesucristo con un encuentro personal con el Señor, el convocar a la Iglesia a un estado de misión, la sensibilidad ante las situaciones injustas y dolorosas del pueblo y la renovación de la opción por los pobres hoy excluidos, la necesidad de la formación y de una catequesis no intimista, el defender el protagonismo de los laicos y, singularmente, el de la mujer en la Iglesia y en la sociedad, la importancia dada a la Palabra y a la eucaristía, la necesidad de vivir la fe en las diversas comunidades eclesiales existentes, el hacer de la Iglesia una abogada de la justicia, la presencia de la Iglesia en el mundo, la preocupación por la familia, por la pastoral urbana, por los medios de comunicación, por la ecología, la valoración positiva de la religiosidad popular, el alentar la esperanza... Algunos dicen que la teología de la liberación ha sido implícitamente reafirmada; otros, que Aparecida ha sido un serio paso hacia adelante.

Entre las sombras se señala que hay miedo a analizar la realidad en sí misma antes de dar sobre ella un diagnóstico a la luz de la fe, se constata la pobreza, pero no se investigan las causas profundas de esta situación injusta, ni hay una condena explícita del sistema neoliberal. La preocupación del Documento es ma- 
yormente intraeclesial, incluso parece más preocupado por la identidad católica que por la identidad cristiana y no se reflexiona sobre las causas estructurales de las debilidades de la Iglesia. La dimensión del reino, aunque no ausente, no es decisiva en la eclesiología del Documento. La cristología es débil, no se resalta el significado profundo de la vida de Jesús de Nazaret, su anuncio del reino y el conflicto que lo llevó a la cruz. Se habla de la importancia central de la eucaristía en la Iglesia y del domingo, pero ante la falta de sacerdotes para la celebración de la eucaristía no se toman opciones radicales sobre los ministerios. Se habla del laicado, pero se piensa sobre todo en los nuevos movimientos eclesiales. Se exhorta positivamente al compromiso social del laicado, pero algunos tienen la impresión de que la Iglesia aparece como un asunto puramente clerical. La vida religiosa es poco resaltada y se la acusa de recaídas secularizantes, influidas por una antropología sociológica y poco evangélica. Hay una gran dispersión en las opciones de Aparecida, sin una prioridad pastoral clara: niños, jóvenes, indígenas y afroamericanos, encarcelados, matrimonios y familias, ciudades, medios de comunicación, dirigentes sociales, refugiados, drogadictos, enfermos, ancianos, alejados, mujeres, varones, nuevos areópagos, educación, cultura de la vida, ecología y medio ambiente. Existe una yuxtaposición de líneas teológicas y pastorales, fruto de un mutuo acuerdo, pero sin llegar a un consenso de fondo: se habla de comunidades de base, pero se resaltan sobre todo los nuevos movimientos eclesiales; se habla de la mujer, pero se critica la ideología de género...

Algunos lamentan también que no se haya tomado en serio el fenómeno del pentecostalismo, otros que no se haya dado un grito profético a favor de la Amazonia y de la ecología, ya que está en peligro la supervivencia humana. Se preguntan algunos si en Aparecida no habrá una oculta añoranza de la cristiandad, de una Iglesia de masas y, por esto, en un momento de crisis eclesial, se quiere realizar un último esfuerzo de marketing evangélico, propugnando una gran misión continental. Alguno ha dicho de Aparecida que es más cemento que fermento. Muchos opinan que el discurso de Benedicto XVI fue mucho más valiente y profético que el Documento final.

\section{Los cambios en el documento conclusivo}

Especialmente críticos han sido los comentarios acerca de los cambios que se han producido entre el Documento aprobado por los obispos en Aparecida y el Documento conclusivo oficial aprobado por Roma. Son muy numerosas las correcciones que afectan a diversos temas: a la realidad social (se le quita mordiente al análisis del sistema injusto, que amenaza la vida), a la cristología (se debilita la visión bíblica en favor de una acentuación dogmática y espiritual, menos encarnada), a la relación Iglesia mundo (hay miedo a aceptar la densidad teologal de la vida de la humanidad fuera de la Iglesia), a la Iglesia (no se quiere aceptar el clericalismo, ni el pecado social y estructural de la Iglesia), a la comunidad y sus ministerios (se debilita la fraternidad comunitaria, se acentúa 
fuertemente la distancia entre clérigos, se omite la referencia al florecimiento del diaconado permanente y a la exigencia de impulsarlo), a las comunidades de base (quedan muy debilitadas, empobrecidas, casi objeto de sospecha, mientras se refuerzan los nuevos movimientos eclesiales), a la Biblia (hay como miedo a que la Palabra opaque la práctica sacramental), al ecumenismo (miedo a que se pierda la identidad de católica), etc.

Da la impresión de que los censores romanos no acaban de aceptar la peculiaridad del caminar de la Iglesia latinoamericana, en lo que tiene de más original, y quieren desdibujar el proceso latinoamericano, con la excusa de igualarlo de forma uniforme al del resto de la Iglesia universal. Esto significaría no reconocer el derecho legítimo de una configuración propia de las diversas iglesias locales, opción que el Vaticano II había defendido.

Esta compleja situación, llena de interrogantes, provoca perplejidad y dificulta la lectura del Documento de Aparecida, pues aunque el evento eclesial de Aparecida es más que el Documento, éste ha de ser siempre el punto de referencia. ¿Cómo superar este conflicto de interpretaciones? ¿Cómo aprovechar todo lo bueno que contiene y hacer una recepción positiva, poniendo a producir pastoralmente el texto, de modo que sea realmente eficaz? ¿Qué hacer para no escandalizar al pueblo, pero sin tampoco mantenerlo en una minoría de edad? ¿Cómo ayudar al pueblo a crecer en su fe y en su ser eclesial, hacerle tomar conciencia de que todo bautizado ha de ser discípulo y misionero? ¿Cómo suscitar esperanza en el pueblo? ¿Por dónde comenzar? ¿Qué clave de lectura podría ayudar a la lectura y comprensión de Aparecida?

\section{En busca de una clave hermenéutica de lectura}

Naturalmente, se puede iniciar la lectura de Aparecida haciendo un recorrido por sus tres partes y explicando el contenido de cada una de ellas.

La primera parte, La vida de nuestros pueblos hoy (capítulos 1 y 2), contempla la realidad social y eclesial de América Latina y del Caribe con sus luces y sus sombras. Corresponde al "ver" del método latinoamericano.

La segunda parte, el "juzgar", se centra en el discipulado y la misión: La vida de Jesucristo en los discípulos y misioneros (capítulos 3-6), para así iluminar la vocación misionera de los discípulos.

La tercera parte, La vida de Jesucristo para nuestros pueblos (capítulos 710 ), corresponde al actuar y propone diversas opciones pastorales.

Pero ¿cómo hallar una clave unitaria, que oriente la lectura de estas diversas partes y nos dé el sentido global del Documento, con una hermenéutica correcta? ¿Cuál es el trasfondo de todo el Documento? 


\subsection{La crisis galilea}

Quizá antes de abordar el Documento de Aparecida podría ayudar el distanciarnos un poco de él y recordar un momento crítico de la vida de Jesús, al que hacen alusión los evangelios, tanto los sinópticos, como el de Juan. Es lo que se suele conocer como "la crisis galilea".

Jesús, después de sus éxitos iniciales por su predicación y milagros que provocaron que grandes multitudes lo siguieran, comienza a percibir un cambio de situación. Por una parte, los jefes de su pueblo, sacerdotes, escribas y fariseos, están cada vez más en contra suya y no disimulan su rechazo y hostilidad, lo cual ya preludia su pasión futura. Pero incluso dentro del mismo pueblo, que hasta entonces lo seguía, algunos grupos lo abandonan al no ver en Jesús al Mesías rey que esperaban ("el asunto de los panes", según Marcos 6, 52). Otros grupos no lo abandonan, pero no lo comprenden.

Esto obliga a Jesús a repensar y replantear su misión, abandona Galilea y se dirige a los territorios paganos, a Cesarea de Filipo y a la frontera siro-fenicia. En este nuevo escenario geográfico y religioso, comienza a cambiar de táctica: ya no se dirige tanto a las multitudes anunciándoles el reino, no hace milagros, no expulsa demonios, no come con pecadores, sino que se concentra más bien en el grupo más reducido de los suyos, se consagra a formar a los discípulos, a consolidar su comunidad.

En esta nueva opción, les imparte nuevas instrucciones sobre la actitud de servicio que deben tener, que no pretendan obtener los primeros puestos como los jefes de este mundo, les habla de las condiciones del seguimiento (Mc 8, 34-38; Mt 16, 24-28; Lc 9, 23-27), les anuncia su pasión, les dice que él ha venido a servir y no a ser servido (Mc 10, 31-45). En este contexto, les pregunta quién dice la gente que es él y qué opinan ellos. A Pedro, que confiesa que Él es el Cristo, lo llama roca, pero también Satanás y piedra de escándalo, porque no acepta su pasión (Mc 8, 27-30; Mt 16, 13-28; Lc 9, 18-26). Más tarde, se transfigura ante sus tres discípulos predilectos, para que no se escandalicen de la futura pasión (Mc 9, 2-8; Mt 17, 1-8; Lc 9, 28-36).

También en el evangelio de Juan aparece la crisis después de la multiplicación de los panes, cuando Jesús huye para no ser proclamado rey $(J n$ 6, 15). Y después del discurso del pan de vida en Cafarnaum, ante el escándalo y la deserción de algunos discípulos, pregunta a los suyos si ellos también desean irse y dejarlo, lo que provoca la reacción valiente de Pedro, que lo reconoce como el que tiene palabras de vida eterna (Jn 6,67-71). Luego, Jesús se dirige a la otra orilla del Jordán (Jn 10, 40) y a Betania (Jn 11-12, 10).

En síntesis, el enfrentamiento con las autoridades religiosas de Israel y la incomprensión del pueblo, obligan a Jesús a una concentración en la comunidad de sus discípulos, a reforzar su identidad. Pero, al adoptar esta táctica pastoral, 
Jesús no da marcha atrás a su misión, no renuncia a sus opciones, ni a su proyecto del reino, sigue caminando a Jerusalén, hacia la pascua. De este grupo de discípulos temerosos nacerá, después de pascua y pentecostés, la comunidad misionera de los apóstoles de la Iglesia.

\subsection{Analogía con América Latina}

Hay una cierta analogía entre la crisis de Galilea y la situación de América Latina. La Iglesia latinoamericana y del Caribe ha sido considerada durante mucho tiempo como "el continente de la esperanza", con el mayor contingente de católicos, frente a una Iglesia que decrece en Europa y América del Norte y es minoritaria en Asia y África. América Latina era vista como una especie de "Amazonia espiritual" de la Iglesia, la reserva oxigenante del catolicismo, en medio de un mundo contaminado. Pues bien, ahora, así como la Amazonía está en riesgo (85-86), también la Iglesia de América Latina y del Caribe parece haber entrado en una situación de crisis: no sólo es el continente cristiano con mayores desigualdades sociales, sino que se percibe una debilidad en la fe, hay un gran divorcio entre la fe y la vida, falta formación cristiana, disminuyen las vocaciones, hay poco sentido de pertenencia eclesial y del ser discípulos y misioneros, la rica religiosidad popular está muy al margen de la Iglesia institucional, crecen la indiferencia religiosa y el agnosticismo, muchos dejan la Iglesia católica para hacerse miembros de otras comunidades cristianas, algunos se adhieren a las religiones originarias o a otras confesiones religiosas. Aunque la Iglesia en América Latina y en el Caribe posee grupos y personas realmente testigos admirables de la fe, en su conjunto, la Iglesia pierde adeptos, y como colectividad, constituye un signo débil del reino, en la sociedad de hoy.

Frente a esta realidad es coherente que, como en la crisis galilea de Jesús, los obispos de América Latina y del Caribe, reunidos en Aparecida, con una visión pastoral que va más allá de sus diferencias ideológicas y doctrinales, hayan propuesto una cierta concentración eclesial: profundizar la identidad cristiana de los bautizados para que sean discípulos y misioneros de Jesucristo, en orden a que nuestros pueblos en Él tengan vida plena.

Este me parece ser el trasfondo básico de Aparecida, el backgrouná eclesial, el Sitz im Leben o el contexto vital que permite entender su punto de partida, sus retos, su novedad y sus opciones fundamentales. Y también sus riesgos: si esta concentración eclesial no se abre decididamente al reino, a la sociedad, a la justicia, a los pobres, a los signos de los tiempos, Aparecida podría desembocar en un eclesiocentrismo y conducir a una nueva cristiandad.

A partir de esta situación vital como clave hermenéutica, vamos a intentar leer Aparecida, desentrañando sus tesis de fondo. 


\section{Una guía de lectura de Aparecida}

Es imposible señalar todos los aportes del Documento de Aparecida, ni sería pedagógico hacer un índice de todos sus temas. Por eso, aun a riesgo de subjetivismo, a partir de la clave de lectura antes señalada, vamos a desarrollar un hilo conductor que oriente todo el Documento, aunque las afirmaciones o líneas de fondo que expondremos no se encuentren siempre explícitamente formuladas en el texto del Documento

\subsection{Crisis y debilitamiento de la fe cristiana}

El Documento comienza con una buena síntesis de la realidad social, económica, política y cultural del continente (33-97), pero el interés de los obispos se centra sobre todo en la situación eclesial (98-100). Lo mismo hizo el Papa, en su discurso inaugural (DI 1-4).

El Documento agradece a Dios el gran don de la fe y señala los aspectos positivos de la vida eclesial latinoamericana: la fe profunda del pueblo, el valor de la religiosidad popular, el compromiso eclesial con los pobres y la dignidad humana, la renovación bíblica, catequética y litúrgica, la vitalidad de las parroquias y de la vida consagrada, el trabajo en las diversas pastorales específicas, el testimonio de los laicos, la riqueza de las diversas comunidades, etc. (98-99)

Pero también señala sus sombras: un debilitamiento de la vida cristiana en su conjunto y de la pertenencia a la Iglesia, como ya señaló Benedicto XVI, en su Discurso inaugural (DI 2). Hay clericalismo, individualismo, marginación de la mujer, sacramentalismo con falta de evangelización, poco compromiso de los laicos en la vida social, disminución del clero y de la vida religiosa, materialismo y falta de sentido de trascendencia, abandono de las prácticas religiosas y de la pertenencia a la Iglesia, paso a otros grupos religiosos (100).

Una lectura atenta del Documento nos lleva a la conclusión de que hay en los obispos una seria preocupación pastoral por la pérdida de vitalidad de la Iglesia. La introducción al Documento es muy clara a este respecto. Citaremos tan sólo un texto de gran lucidez pastoral.

No resistiría ${ }^{2}$ a los embates del tiempo una fe católica reducida a bagaje, a elenco de normas y prohibiciones, a prácticas de devoción fragmentadas, a adhesiones selectivas y parciales de las verdades de la fe, a una participación ocasional en algunos sacramentos, a la repetición de principios doctrinales, a moralismos blandos o crispados que no convierten la vida de los bautizados (12).

2. E1 Documento aprobado por los obispos, en lugar del futuro condicional "no resistiría", con un sentido más presente y realista, decía "no resiste". 
Los obispos perciben claramente que la actual situación eclesial es crítica, la fe se erosiona $(13,38)$, se necesita un fuerte correctivo, una auténtica conversión pastoral si no se quiere degenerar en descristianización como ha sucedido en otros continentes. Por esto se habla de custodiar y alimentar la fe del pueblo (10), de confirmar, renovar, revitalizar la novedad del evangelio (11).

El Documento parece señalar que esta crisis se debe a "los embates del tiempo", pero podemos preguntarnos si no hay también causas eclesiales, tanto históricas, ligadas a la primera evangelización, como actuales, relacionadas con actitudes de la Iglesia universal y de la Iglesia latinoamericana. El Documento no incide en este necesario análisis estructural de la Iglesia pero, indirectamente, al proponer algunas soluciones, indica algunas de las causas.

\subsection{Necesidad de revitalizar nuestra fe con un encuentro personal con Cristo}

Ante esta crítica situación, Aparecida llama a una auténtica renovación de la vida cristiana, a revitalizar la novedad del evangelio, a repensar y relanzar su misión (10), a recomenzar desde Cristo, a reasumir el sentido del bautismo ${ }^{3}$. El gran reto de la Iglesia es formar discípulos y misioneros (14).

Para ello, siguiendo a Benedicto XVI, reconoce que "no se comienza a ser cristiano por una decisión ética o una gran idea, sino por el encuentro con un acontecimiento, con una Persona, que da un nuevo horizonte a la vida, y con ello, una orientación decisiva" (12, cita de Dios es amor n 1)4.

Esta experiencia personal y espiritual con el Señor es la que da sentido a la vida cristiana, la que nos hace discípulos y misioneros, como aconteció con los primeros discípulos de Jesús (Jn 1, 35-39; 243-244). Este encuentro personal con el Señor se realiza en la Escritura (247-249), en la liturgia, sobre todo eucarística (250-255), en la comunidad cristiana (256), en los pobres (257), en la religiosidad y piedad popular (258-265). Sin esta experiencia no hay vida cristiana auténtica, sino todo lo más ideología, moralismo y ritualismo. En el fondo se dice de nuevo que América Latina necesita una nueva evangelización, pues no basta una praxis sacramental ocasional. Sin esta evangelización renovada no habrá discípulos, ni misioneros, sino solamente cristianos por tradición y costumbre cultural. Esta situación ya no será sostenible en el futuro.

3. Se ha observado la frecuencia del prefijo "re" en el Documento: renovar, revitalizar, recomenzar, relanzar, recuperar... lo cual indica que se requiere volver a las raíces de la identidad cristiana.

4. En el índice analítico hay una larga serie de números sobre el encuentro personal con Cristo: 11, 12, 13, 14, 21 ,28, 29, 95, 99, 145, 154, 167, 175,181, 226, 242 ,246, 249, $250,251,257,258,259,263,270,273,278,280,189,290,305,322,319,336$,343, $350,364,417,446,500,548,549$. Esto indica que se trata de un tema fundamental. 


\subsection{Exigencia de una formación cristiana}

Aparecida dedica todo un capítulo (capítulo 6) al itinerario formativo de los discípulos misioneros y habla de una opción por la formación cristiana (276) . Esto supone todo un proceso, que incluye el anuncio del kerygma que posibilite un encuentro personal con Jesucristo, la conversión, el discipulado, la comunión eclesial y la misión para anunciar a Cristo $(278)^{6}$. Esta formación cristiana tiene dos momentos fuertes, el de la iniciación a la vida cristiana -bautismo, confirmación y eucaristía, con la catequesis correspondiente- (286-294) y la catequesis permanente o catequesis de adultos (295-300). Se trata de iniciar a la vida cristiana en su globalidad, más que limitarse a la iniciación a los sacramentos.

Este itinerario supone un acompañamiento respetuoso de las situaciones diversas (280), acompañando la fe ya presente en la religiosidad popular (258). Esta formación requiere la acción decidida de las diversas comunidades cristianas: familia (302-303), parroquias (304-306), pequeñas comunidades eclesiales (307-310), movimientos eclesiales y nuevas comunidades (311-313), así como también de los seminarios y casas de formación religiosa (314-327) y de los diversos centros de educación católica, tanto colegios como universidades (328-346).

Esta insistencia en la formación cristiana nos parece una de las mayores novedades de Aparecida y responde a la preocupación pastoral de los obispos por fortalecer la fe débil del pueblo. Seguramente, se ha constatado que la práctica litúrgica de muchos fieles no está precedida, ni acompañada de una necesaria evangelización (anuncio, catequesis, formación teológica...). La Palabra no ilumina debidamente la celebración sacramental, ni la vida, lo cual tiene el riesgo de degenerar en un ritualismo, vacío de contenidos de fe y sin una praxis cristiana coherente.

Permanecen sin duda interrogantes abiertos sobre cómo realizar esta formación, no sólo con los sectores de alto nivel social y más educados, sino también con los sectores populares, que disponen de menos medios de formación y de menos tiempo. Sin embargo, no debemos olvidar que estos sectores pobres (indígenas y afroamericanos, obreros, mineros, campesinos, habitantes de barrios suburbanos periféricos...) deberían ser prioritarios en la preocupación pastoral de la Iglesia, ya que son los preferidos del Señor y a ellos han sido revelados los misterios del reino, ocultos a los sabios e inteligentes de este mundo (Lc 10, 21).

5. En la carta de Benedicto XVI a los obispos de América Latina y del Caribe, promulgando el Documento conclusivo, constata entre las ricas reflexiones e indicaciones pastorales, la prioridad dada a "reforzar la formación cristiana de los fieles en general y de los agentes de pastoral en particular".

6. Se ha hecho notar que este itinerario está muy influido por el camino neocatecumenal. 


\subsection{Inserción en la comunidad eclesial}

En estrecha relación con la opción anterior aparece la preocupación de Aparecida por la inserción de los fieles en la comunidad eclesial, sin lo cual no hay auténtica vida cristiana (154-163). Se señalan los principales lugares eclesiales para esta comunión: la diócesis (164-169), la parroquia como comunidad de comunidades (170-177), las comunidades eclesiales de base y las pequeñas comunidades (178-180). Evidentemente, el centro de esta dimensión comunitaria es la celebración eucarística, sobre todo dominical, momento fuerte de la fe cristiana $(158 ; 165 ; 175 \ldots)$

Esta preocupación por la dimensión comunitaria de la vida de los discípulos y misioneros responde a la persuasión de los obispos de que muchos cristianos viven su fe de forma muy individualista, sin ninguna vinculación estable con una comunidad cristiana, a la cual muchos acuden sólo puntualmente con ocasión de algunos sacramentos. De aquí se deduce que la tarea a la que debe orientarse tanto la evangelización como la liturgia es la formación de la comunidad cristiana, sin la cual ni la fe se mantiene, ni el sacramento produce su fruto auténtico. Esto supone una verdadera conversión pastoral.

\subsection{Dimensión social de la misión}

Todo lo anterior quedaría reducido a un eclesiocentrismo centrípeto si no se insistiese en la dimensión social del discípulo-misionero. La tercera parte de Aparecida está consagrada al objetivo de comunicar vida a nuestros pueblos.

Esta vida alcanza su plenitud en el anuncio de Cristo a todos, pero esta evangelización "incluye la opción por los pobres, la promoción humana integral y una auténtica liberación cristiana" (147). Ya el papa, en su Discurso inaugural, había insistido en la necesidad de una catequesis social (Dl 3; cfr. 505) y había afirmado que "la opción por los pobres está implícita en la fe cristológica" (DI n 3; cfr. 392). Aparecida, que en la primera parte había descrito con crudeza la dramática situación de pobreza injusta del continente y los nuevos rostros de pobreza (65), en la tercera parte nos propone que la Iglesia se abra al reino de Dios y a la promoción de la dignidad humana (capítulo $8,380-430$ ).

Aparecida desarrolla ampliamente esta dimensión social del compromiso cristiano, al servicio de una vida plena para todos (358). Por esto, renueva la opción preferencial por los pobres y excluidos (391-398) y propone una pastoral social para la promoción humana integral (399-405), con una preocupación especial por algunos rostros que más duelen: los que viven en las calles de las grandes ciudades (407-410), migrantes (411-416), enfermos (417-421), adictodependientes (422-426), detenidos en cárceles (427-430). La Iglesia ha de ser "abogada de la justicia, defensora de los pobres, ante las intolerables desigualdades sociales y económicas que claman al cielo“ (395). 
Frente a la privatización de la fe, Aparecida insiste en el compromiso social, en especial de los laicos, para que actúen en el mundo de la política, de la realidad social, de la economía, de la cultura, de las ciencias, de los medios de comunicación $(174,371,403,406,508)$.

Sólo una fe coherente con la praxis de la justicia al servicio de la vida, superará el actual divorcio entre la fe y la vida.

\section{Conclusión}

Aparecida nos invita a una conversión personal y eclesial, a pasar de una pastoral de conservación a una pastoral misionera (370), a tener un encuentro personal con Cristo, que nos lleve a una vida de fe profunda y madura, inserta en la comunidad eclesial misionera, abierta a las exigencias sociales, a un compromiso por la justicia del reino de Dios, a defender la vida amenazada y a suscitar una vida plena en un mundo marcado por la injusticia y la muerte. En conclusión, Aparecida pide que la Iglesia en América Latina y en el Caribe se convierta en un signo transparente y eficaz del reino de Dios. Y todo ello, con el soplo potente del Espíritu (551).

En la situación de cambios sociales, políticos, económicos, culturales y también religiosos que vive actualmente Bolivia, Aparecida nos advierte que en el futuro únicamente se podrá mantener una fe cristiana que pase de ser una simple costumbre y tradición a ser una respuesta personal al evangelio, que nos convierta en discípulos y misioneros, una fe vivida en la comunidad eclesial, profundizada en una formación cristiana permanente, que dialogue con las culturas y se comprometa en el cambio a una sociedad más igualitaria y justa.

Aparecida puede ser para la Iglesia de Bolivia una ocasión privilegiada, un kairós, para iniciar este proceso de cambio eclesial y social, que sea un signo de esperanza para el pueblo. Pero no habrá cambio de estructuras eclesiales y sociales sin un cambio personal, sin hombres y mujeres nuevos (11).

¿No es también esta misma búsqueda de mayor radicalidad lo que en la crisis de Galilea impulsó a Jesús a formar una comunidad de discípulos y misioneros, futuros apóstoles de la Iglesia? 